\title{
BIFROST project: 3-D crustal deformation rates derived from GPS confirm postglacial rebound in Fennoscandia
}

\author{
Hans-Georg Scherneck ${ }^{1}$, Jan M. Johansson ${ }^{1}$, Martin Vermeer ${ }^{2}$, James L. Davis ${ }^{3}$, Glenn A. Milne ${ }^{4}$, and Jerry X. Mitrovica ${ }^{5}$ \\ ${ }^{1}$ Chalmers, Onsala Space Observatory, SE-439 92 Onsala, Sweden \\ ${ }^{2}$ Finnish Geodetic Institute, PL 15, FI-02431 Masala, Finland \\ ${ }^{3}$ Harvard-Smithsonian Center for Astrophysics, Cambridge, MA 02133, U.S.A. \\ ${ }^{4}$ Department of Geological Sciences, University of Durham, Durham, GH1 3LE, U.K. \\ ${ }^{5}$ Department of Physics, University of Toronto, Toronto, Ontario, Canada M5S $1 A 7$ \\ (Received January 17, 2000; Revised July 11, 2000; Accepted March 26, 2001)
}

\begin{abstract}
Since autumn 1993 the BIFROST project has provided daily GPS solutions of geodetic positions from a network of more than 40 stations covering a large area of the Baltic shield. This area is expected to show large vertical motion due to glacial isostatic rebound following the deglaciation at the end of the Pleistocene. This paper will discuss the inference of three-dimensional rates of crustal motion at the GPS stations with respect to (1) a plate-fixed average for the horizontal components; (2) a geocentric reference in order to infer absolute changes of sea level from vertical crustal motion and models of geoidal rebound. We show that the horizontal strain rate pattern is largely dominated by unilateral extension and not exhibiting horizontal shear to an important extent. In regard to the vertical motion a crucial issue is the stability of the geocentre in the GPS frame. We show results from an Empirical Orthogonal Function analysis that attenuates regionally correlated noise. In all components our observations suggest reasonably close agreement with forward computions on the basis of postglacial isostatic adjustment. A dominant tectonic signal would lead to a certain fraction of the batch of baselines to exhibit shortening. A tectonic process leading to a similar pattern of horizontal motion as expected from postglacial rebound can safely be dismissed in the context of the currently accepted plate tectonic setting. Thus, our baseline rate comparison will be a critical first order test of the prevailing style of deformation.
\end{abstract}

\section{Introduction}

The BIFROST project was started in 1993 to employ continuous GPS observations at permanent stations for primarily the measurement of vertical crustal motion (BIFROST et al., 1996; Scherneck et al., 1998). During planning for the project it became clear that measurements of contemporary motion related to the isostatic rebound in response to the retreat of the Pleistocene ice sheet in Fennoscandia and ensuing sea level changes (as a consequence of a global change in land ice mass) would demand a precision in the lower range of tenths of millimetre per year. This precision is needed to add significantly new information to the studies of this problem (Ekman, 1988; Douglas, 1991, 1992; Tushingham and Peltier, 1991; Mitrovica and Peltier, 1991; Mitrovica et al., 1994a; Ekman, 1996; Lambeck et al., 1998).

With VLBI (Very Long Baseline Interferometry), SLR (Satellite Laser Ranging), and GPS space geodesy appears to offer the required resolution from reasonable observation time spans (one decade). Space geodetic techniques also create qualitatively new information. The vertical motion of the crust is observed independently of a regional height reference like mean sea level or temporally changing geoid. The capability to observe horizontal displacement

Copy right(c) The Society of Geomagnetism and Earth, Planetary and Space Sciences (SGEPSS); The Seismological Society of Japan; The Volcanological Society of Japan; The Geodetic Society of Japan; The Japanese Society for Planetary Sciences. over medium to large distances at a precision prospectively better than $10^{-10} / \mathrm{yr}(0.1 \mathrm{~mm} / \mathrm{yr}$ over $1000 \mathrm{~km})$ adds two additional spatial components, which cannot be achieved with any ground-based technique.

However, neither VLBI nor SLR networks have been designed especially for this application, with the consequence that the field of motion is sampled in a station geometry that is far from optimum. Thus, the systematic pattern of tangential velocities radiating outward from the uplift centres can be difficult to separate from plate tectonic motion (James and Lambert, 1993; Argus et al., 1999). GPS offers the currently most cost-efficient method to tailor dense observation networks for continuous monitoring.

By comparison with tide gauge observations, the crustal motion at the gauges can be inferred and a regional change of absolute sea level thus be determined. The relatively large number of tide gauges in the area can thus contribute to sea level studies on a global scale (Carter, 1994; Davis et al., 1999).

The horizontal observations can be shown to add critical information that render the inverse solutions for mantle viscosity structure and lithosphere thickness more unique and place tighter bounds on ice shield parameters (James and Morgan, 1990; Mitrovica et al., 1994a, b; Scherneck et al., 1999). Many space geodetic techniques have the sensitivity to recover horizontal deformation components due to post- 
glacial rebound (James and Lambert, 1993; Mitrovica et al., 1993; Argus et al., 1999; Campbell and Nothnagel, 2000; Haas et al., 2000).

\section{Background}

From a plate tectonic perspective one should expect the interior of a continental shield away from known zones of orogeny to deform at very low rates. The term "rigid plate" has been coined to contrast interaction at plate boundaries. To expect absolute rigidity, however, is certainly not realistic, but rather a range of small deviations from stability. Seismicity might be a strong indicator, especially in a prevailing compressive stress background as appears to be the case in Fennoscandia (Brereton and Müller, 1991; Müller et al., 1992; Steinberger et al., 2001).

As regards earthquakes the Fennoscandian shield is not totally inactive. Zones where seismicity has a regional maximum are found along the Norwegian coast, in the northern central parts of the shield, along the western coast of the Gulf of Bothnia, and around the great lakes in Southern Sweden, while lowest levels are reached in the southern half of Finland (Ahjos and Uski, 1992; Arvidsson and Kulhánek, 1994). The seismically most active zones appear to correlate with known fault zones (Talbot and Slunga, 1989). Several indicators suggest low levels of coseismic strain release in the interior of the shield, i.e. the area covered by the GPS networks. These are (1) maximum expected accelerations as shown in the Global Seismic Hazard Assessment Project's map (Grünthal et al., 1999) being an order of magnitude below the levels found e.g. in the Alpine belt; (2) maximum expected local magnitude $\left(M_{L}\right)$ at about 4.5 (Kijko et al., 1993; the three Fennoscandian earthquakes exceeding $M_{L}=5$ occurred at peripheral locations, cf. Muir-Wood, 1988), and in the Oslo Fjord 1904); (3) $b$-values of the Gutenberg-Richter spectrum between 0.8 and 1.5 in combination with low levels of energy release (Skordas and Kulhánek, 1992); and (4) deep (20 to $40 \mathrm{~km}$ ) hypocentre locations of the majority of the larger events (Arvidsson and Kulhánek, 1994).

The earthquake activity seems to indicate ongoing deformation of the shield, albeit at a low level. Since a correlation between the rebound and seismicity is still remaining unclear (Gregersen, 1992) either a combination of plate tectonic stresses and rebound stresses or a leading role of the former might have to be advocated. The low seismicity levels and low magnitude of the greatest expected earthquake suggest localised strain release to have a low impact on the BIFROST network. The network would then observe primarily the elastically released strain of the crust, which is more evenly distributed. However, there is an open debate after propositions of large ratios between aseismically and coseismically released strain in the fault zones and even outside (Slunga, 1991) referring to results from triangulation and trilateration in Finland Kakkuri and Chen, 1992). Campaign-based GPS studies in Sweden claim motions of $1-3 \mathrm{~mm} / \mathrm{yr}$ both at or below a $200 \mathrm{~km}$ scale (in the Scania province around the Törnquist zone, Pan et al., 1999) and across fault zones at the shield scale Pan and Sjöberg, 1999).

In other parts of the world, either the motions observed in campaign work are much larger (e.g. Kahle et al., 1999) or small motions are studied with continuous methods (e.g.
Bennett et al., 1999). We hope that our work can contribute unique evidence as to the importance of faulting and the hypothesis of large, aseismic slip for deformation in Fennoscandia.

At this early stage of the BIFROST project the horizontal data has not yet obtained the necessary homogeneity in precision and accuracy required for a detailed inversion and safe interpretation of tectonically active zones. Therefore, it appears appropriate to aim at a first order comparison of predicted rebound motion and GPS observations and from that gain a parameter representative for the goodness of fit.

Fortunately, the expected horizontal rebound component has a unique property - the deformation is dominated by surface extension throughout the uplift area. Thus, baseline length would be increasing throughout and be only weakly dependent of azimuth (following the circular asymmetry of the uplift pattern), whereas tectonically dominated motion would have a considerable degree of shear (Talbot and Slunga, 1989). Also, the brittle-ductile response of Fennoscandia in the ambient stress field related to NorthAtlantic sea floor spreading and sub-lithospheric stress transfer is forced to have compressional components. A dominant tectonic signal would lead to a certain fraction of the batch of baselines to exhibit shortening. A tectonic process leading to a similar pattern of horizontal motion as expected from postglacial rebound can safely be dismissed in the context of the currently accepted plate tectonic setting. Thus, our baseline rate comparison will be a critical first order test of the prevailing style of deformation.

\section{Data Analysis}

Our inference of motions proceeds in several steps: daily analysis of observations; simple analysis within a Europefixed frame of motion on a per-site basis from the complete daily data base; and a stage where the longest time-series are used to construct a basis for Empirical Orthogonal Functions (EOF) for the reduction of regionally coherent noises.

\subsection{Daily GPS analysis}

GPS data analysis employs GIPSY/OASIS-II (Webb and Zumberge, 1993). More details will be given in a forthcoming paper (Johansson et al., 2001). From September 1996 on we use nonfiducial GPS orbits from JPL, which are expected to reduce inherent ITRF biases that are conveyed through the IGS orbits. Before September 1996 we used IGS orbits, which are tied to certain ITRF epochs.

\subsection{Time series of geodetic positions}

The results of the day by day processing are first reduced with a rigid rotation, where the rotation rate is obtained from the ITRF96 (Boucher et al., 1996) velocity field at a selected set of European IGS stations. Most of these stations are collocation sites for different space geodetic techniques. The rigid rotation is divised free of translations in order to suppress the vertical components, thus avoiding to bias the vertical motion estimates in the BIFROST network. In this way, the long-term geocentre stability of the reference frame fully controls our vertical components. Also the scale is preserved in this procedure. This is important since within the European bounds of the network, the rebound motion contains a scale-effective component. In the no-net-rotation frame the average rotation of the European stations is on the order of 
$4.6 \mathrm{nrad} / \mathrm{yr}$.

We also derive baseline length estimates with GIPSY/ OASIS-II utilities (Webb and Zumberge, 1993). The observed baseline length has the advantage of being unaffected by orientation and translation of frames and satellite orbits. Due to the regional extent of the network the baselines are more sensitive to horizontal than to vertical motion. Thus, their length change is expected to be a rather clean data set from which inference on the style of deformation might be drawn more safely.

\subsection{Motion detection}

Analysis of motion consists of fitting straight lines to the geodetic positions assuming constant rates of motion. The possible presence of systematic errors, nonwhite noise, irregularities in the data base, and misjudged uncertainties all require attention. We introduce a second analysis stage to take care of regionally correlated errors. The details of this approach will be presented in Johansson et al. (2001); in short, the residuals of the first stage of the analysis are collected within a wide region and subjected to an empirical orthogonal function analysis simultaneously with a renewed straight-line and offset adjustment. The re-imported timeseries show a considerable degree of coherence (cf. Fig. 1). In the EOF approach they are represented by one eigenvalueeigenvector pair. Thus, only the common mode is admitted. However, unlike in the "spatial filter" devised by Wdowinski et al. (1997), the admittance of each individual time-series depends on its correlation with the common mode. This gives the method an adaptive property. In this second stage of the least-squares fit we also include predicted air pressure loading deformations; they are computed with loading Green's function convolution over the global land masses from daily averages of global pressure fields (from the European Centre for Medium Range Weather Forecast).

The horizontal deformation field is invariant with respect to a rigid rotation. For example the Laurentide rebound may induce motion in Europe that is spatially almost constant at some fraction of a mm/yr towards the NW. This component is not included in the NUVEL plate motion model (DeMets et al., 1994). Also, the projection of the GPS positions into the velocity field of the ITRF96 (Boucher et al., 1996) us-

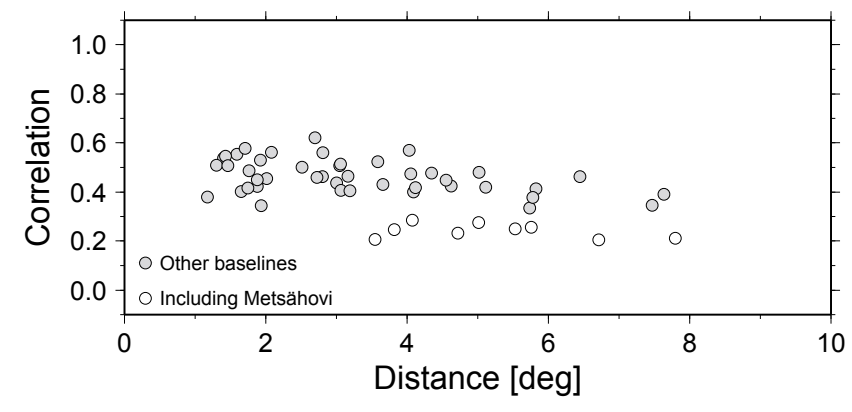

Fig. 1. Pairwise correlation of station residuals (vertical motion) as obtained in the EOF analysis. The correlation is found to have only slight dependence on inter-station distance (abscissa). In the network solutions the Metsähovi site (METS, Finland) is used to tie the solutions into the terrestrial reference frame. This is seen to attenuate common noise signatures. To enhance this feature, open symbols signify correlation between Metsähovi and any other station. ing the actual subset of stations that are in common with BIFROST processing may introduce a rigid rotation bias. We therefore subject the observed horizontal motion, along with their uncertainties, to a rigid adjustment against the predicted horizontal motions before we compare models below.

\section{Rebound Model}

The purpose of this paper is neither to exclude certain sources of motion nor to fine-adjust models, but rather to present a first account of what our observations are indicative of. Consequently we will present a comparison of observed motion with a forward model prediction of 3-D motion due to isostatic rebound after the Pleistocene deglaciation.

The model details will be presented in Milne et al. (2001). It incorporates the ICE-3G model by Tushingham and Peltier (1991) except for Europe where the most recent model by Lambeck et al. (1998) is adopted. The solid earth viscoelastic isostatic part of the model is basically described in Mitrovica et al. (1994a, b). The sea level equations are solved with the iterative algorithm of Mitrovica and Peltier (1991). These equations have recently been extended to include a time-dependent coastline and improved treatment of the ice migration (Milne et al., 1999).

The solid earth parameters adopted in our forward model for the comparison with observations are consistent with the ice-earth-model by both Wieczerkowski et al. (1999) and Lambeck et al. (1998). They consist of a PREM (Anderson and Dziewonski, 1981) density and elasticity structure, with a $71 \mathrm{~km}$ thick elastic lithosphere, and viscosities of $5 \times 10^{20}$ $\mathrm{Pa} \mathrm{s}$ in the upper mantle and $5 \times 10^{21} \mathrm{~Pa} \mathrm{~s}$ in the mantle below $670 \mathrm{~km}$ depth.

\section{Results and Discussion}

The motion detected by BIFROST from observations between September 1993 and December 1997 is shown in Figs. 2 to 4 . For comparison we show the forward modelling results of Section 4. The vertical results are discussed in more detail in Johansson et al. (2001). The normalised $\chi^{2}$ of the vertical motion data decreases from near 100 for a null hypothesis to $2-3$ for the best fit forward model with a $70-100 \mathrm{~km}$ thick lithosphere, $3-5 \times 10^{20} \mathrm{~Pa}$ s upper mantle viscosity and a lower mantle viscosity of at least one order of magnitude greater (Milne et al., 2001).

The geodetic position time-series may, as has been pointed out in Subsection 3.2, contain long-term effects from a weakness in the geocentre parameters. This problem has been pointed out by Argus (1996) with special application to vertical motion in VLBI. We consider the notion of regionally unbiased vertical rates in our efforts important because of the implications on determining sea level changes. Argus (1996) expects the long-term solution of this problem due partly to the large data base that is been built up internationally, and partly to the combination of techniques as this will strengthen the reference frame consistency. Comparison of SLR (Chen et al., 1999) and GPS (Heflin and Watkins, 1999) geocentre series shows that GPS presents less long-term stability. The analysis of Dong et al. (1999) shows 3 to 5 times more signal, and lower correlation with respect to atmospheric and hydrospheric mass centre terms 


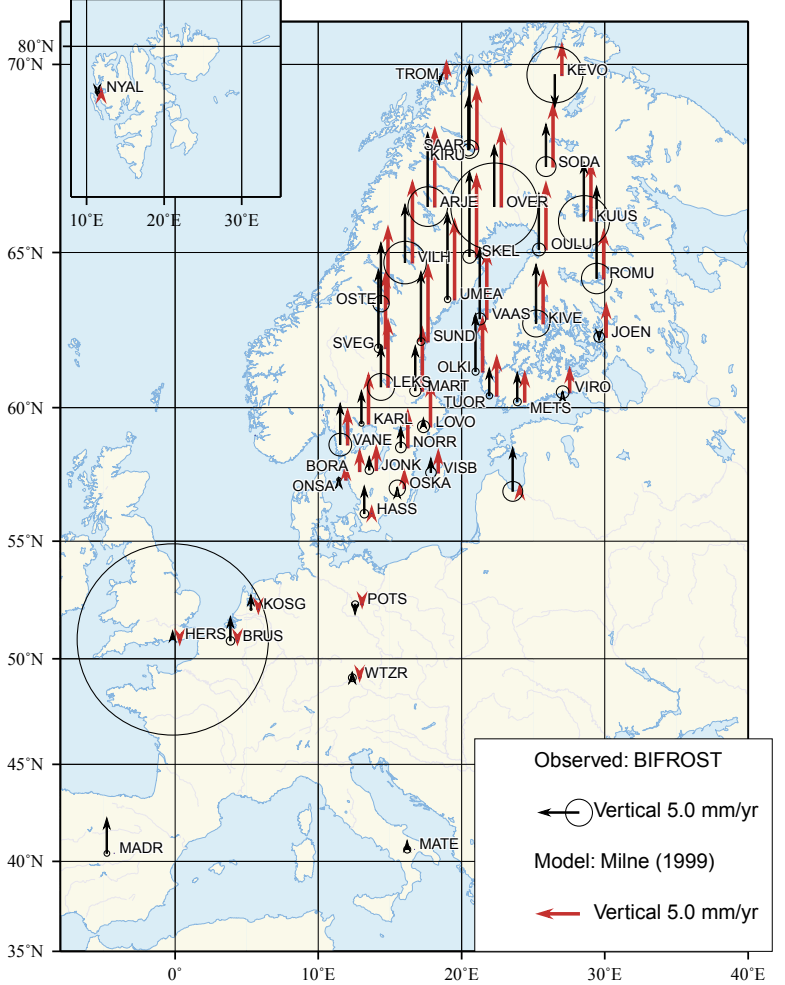

Fig. 2. Predicted present day vertical rates from the viscoelastic earth model and ice history (gray arrows), and observed motion estimated from the BIFROST network (black arrows and confidence circles). Uncertainties represent $1-\sigma$ limits based on a posteriori residual analysis, assuming a Gauss-Markov noise character. Large error ellipses at IGS stations HERS, MADR, and MATE reflect mostly the large a posteriori errors obtained for these stations. In the other cases it is the shorter data history that creates large uncertainties. The arrows signifying the model are plotted with a slight leftward offset for clarity. The model assumes a $71 \mathrm{~km}$ thick elastic lithosphere, and viscosities of $5 \times 10^{20} \mathrm{~Pa}$ s in the upper mantle and $5 \times 10^{21} \mathrm{~Pa} \mathrm{~s}$ in the mantle below $670 \mathrm{~km}$.

than the SLR studies. Collocation of GPS stations with SLR stations and continuing efforts in SLR might turn out crucial in the future to obtain the full precision of GPS over the whole range of parameters, emphasising the problem of determining vertical motion of single stations in a geocentric frame.

Results from a regression between observed and modelled vertical rates $\dot{v}_{\text {obs }}=a+b \dot{v}_{\text {model }}$ show a surprisingly large bias $a=-2.3 \pm 0.3 \mathrm{~mm} / \mathrm{yr}$, but are in excellent agreement with relative rates, $b=1.05 \pm 0.04$.

The horizontal motion is shown in Fig. 3. In order to characterise the error level we have propagated the standard phase measurement error at the front-end (assumed to be $1 \mathrm{~cm}$ ) through the whole system of data analysis. This is the standard deviation depicted in Fig. 2. A posteriori analysis of the residuals shows that the autocovariance can be described sufficiently well with a Gauss-Markov model $c_{x x}(t) \propto \rho^{t}, 0<q<1$. We find this model slightly more in agreement with our data than the flicker-noise model explored by Zhang et al. (1997). Uncertainties of rate estimates in Gauss-Markov noise are greater by a factor of $\sqrt{(1+\rho) /(1-\rho)}$ compared to the same signal embedded in white noise. Typical for our network is $0.3<\rho<0.6$. An additional scaling factor for $\sigma$ needs to be applied to ac-

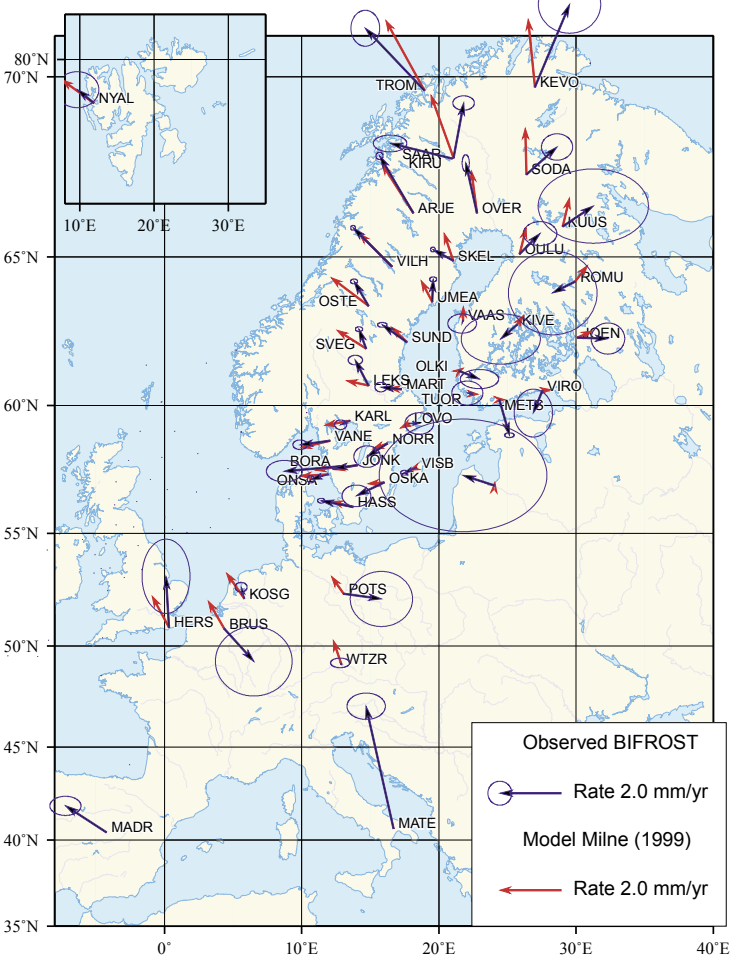

Fig. 3. Same as Fig. 2, horizontal motion, however.

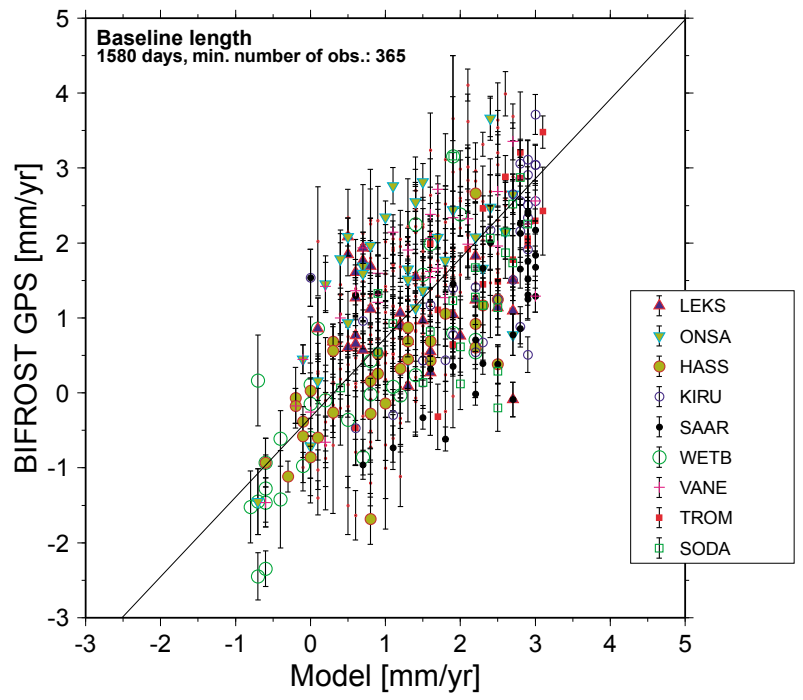

Fig. 4. Baseline rates, GPS results versus forward computations from the isostatic rebound model. Several sites have been marked by symbols in order to emphasise grouping respectively scattering of baselines that have a particular station in common. One group is found to have Wettzell (WETB) in common; these baselines are dominatingly contracting, largely in accordance with the model. Another cluster has SAAR in common, i.e. the ESA station at Kiruna, which forms an obvious outlier group.

count for a large number of effects, of which scattering in the near field of the antennas, uncertainties in the motion field of the reference frames, slowly evolving satellite orbit biases (Heflin and Watkins, 1999) are probably the most important. This scaling factor is obtained a posteriori from the 
residuals of the motion analysis, and amounts typically between 1.5 and 3. It is seen to reflect some degree of regionalised variability (snow problems for instance are enhanced inland).

The horizontal results show a coherent pattern radiating outward from the uplift centre. Several of the data series from Finland are short due to the shorter history of these stations, and do not yet allow to detect motion with a standard deviation less than $1 \mathrm{~mm} / \mathrm{yr}$. We find no indication of deformation exceeding $3 \mathrm{~mm} / \mathrm{yr}$ across the entire shield area. Our findings do not support the results of Kakkuri and Chen (1992), who used repeated optical triangulation and estimated deformations at levels of $1 \mathrm{~cm} / \mathrm{yr}$ over 100 $\mathrm{km}$. Their results appear too close to the standard deviation of 0.1 micro-strain per year to be considered as robust. Also, the resolution of terrestrial methods is too weak for 1 nano-strain per year motions at a scale size of $2000 \mathrm{~km}$. We can also dismiss the results of Pan et al. (1999) who derived horizontal motions from only two GPS campaigns concurrent with BIFROST. These authors clearly underestimate the level of systematic errors by qualifying the uncertainty of their solution only on the basis of the campaign repeatability error.

In Fig. 4 we compare baseline length results in a scatter plot of model versus observation. All baselines in this figure were observed for more than 365 days. The most striking feature is the clear centre of the spread being located in the extensional domain and grouped around a line with a slope of almost unity. A straight-line regression fit has been done assuming weights on the basis of the $a$ priori standard deviation scaled up by two, a typical a posteriori scaling factor based on the motion analysis residuals. It results in a normalised $\chi^{2}$ of 11 (null-hypothesis: 37 ). The baselines that have the station SAAR in common appear to form a group of outliers. This is the IGS station at Kiruna operated by the European Space Agency (ESA). Unlike in a SWEPOS station the SAAR antenna is mounted on a pillar that "floats" in a Quaternary sediment layer. Inspection of baseline length time-series (KIRU-SAAR for instance) shows that motion does not exhibit episodic or seasonally behaviour. This observation calls for further study, but also advises to be cautious in the use of the IGS-KIRU data. Repeating the regression but excluding SAAR the normalised $\chi^{2}$ drops to 8.5 . The slope of the regression line thus obtained is $0.944 \pm 0.015$ and shown in Fig. 4 .

\section{Conclusions}

Geodetic determinations from 1600 days of the operation of BIFROST have provided a data set from which a number of conclusions can be drawn. First, we clearly observe motion in the three spatial directions that is consistent with predictions from a postglacial isostatic rebound model. That model has been developed to fit Quaternary geological observations and tide gauge records (Lambeck et al., 1998) as well as the so-called Fennoscandian relaxation spectrum (Wiezcerkowski et al., 1999). Since our previous report (Scherneck et al., 1998) the solution for horizontal motion has become more consistent. It has started to provide unique evidence that this component of motion is also dominated by the rebound. Since the model has not been inverted in this study to fit the GPS data there is some additional potential signal expected to be explained by a slightly revised rebound model. Eventually existing deformation due to other causes than postglacial rebound may have an upper bound at the $1 \mathrm{~mm} / \mathrm{yr}$ scale. The case of one station not monumented on the special pillar and showing anomalous motion hints at the importance of stable connection to crystalline bedrock.

Our procedure for estimating errors benefits from the large statistical data base obtained in continuous GPS. We have applied a scale factor on our uncertainties of estimated rates that takes into account the Gauss-Markov noise character for which we find evidence from time-series analysis of positions estimates. Regionally coherent noise has been attenuated in a two-stage estimation using empirical orthogonal functions.

Acknowledgments. We thank Bo Jonsson and Gunnar Hedling at the National Land Survey of Sweden and Jorma Jokela, Hannu Koivula, Matti Ollikainen, and Markku Poutanen at the Finnish Geodetic Institute for their great efforts in operating the SWEPOS and FinnRef networks, respectively. Graphics have been prepared with the GMT package provided by Wessel and Smith (1995). This project is supported by grants from the Natural Science Research Council of Sweden under account G-AA/GU 03590. Reviewing suggestions from Thomas James and Erik Ivins have helped to improve this manuscript considerably.

\section{References}

Ahjos, T. and M. Uski, Earthquakes in northern Europe in 1375-1989, Tectonophys., 207, 1-23, 1992.

Anderson, D. L. and A. Dziewonski, Preliminary reference Earth model, Phys. Earth. Planet. Int., 25, 297-356, 1981.

Argus, D., Postglacial rebound in VLBI geodesy: on establishing a vertical reference, Geophys. Res. Lett., 23, 973-976, 1996.

Argus, D., W. R. Peltier, and M. M. Watkins, Glacial isostatic adjustment observed using very long baseline interferometry and satellite laser ranging geodesy, J. Geophys. Res., 104, 29,077-29,093, 1999.

Arvidsson, R. and O. Kulhánek, Seismodynamics of Sweden deduced from earthquake focal mechanisms, Geophys. J. Int., 116, 377-392, 1994.

Bennett, R. A., J. L. Davis, and B. P. Wernicke, Present-day pattern of Cordilleran deformation in the western United States, Geology, 27, 371374, 1999.

BIFROST Project, R. A. Bennett, T. R. Carlsson, T. M. Carlsson, R. Chen, J. L. Davis, M. Ekman, G. Elgered, P. Elósegui, G. Hedling, R. T. K. Jaldehag, P. O. J. Jarlemark, J. M. Johansson, B. Jonsson, J. Kakkuri, H. Koivula, G. A. Milne, J. X. Mitrovica, B. I. Nilsson, M. Ollikainen, M. Paunonen, M. Poutanen, R. N. Pysklywec, B. O. Rönnäng, H.-G. Scherneck, I. I. Shapiro, and M. Vermeer, GPS measurements to constrain geodynamic processes in Fennoscandia, EOS Trans. $A G U, \mathbf{7 7}$, 337, 339, 1996.

Boucher, C., Z. Altamimi, M. Feissel, and P. Sillard, Results and Analysis of the ITRF94, IERS Technical Note 20, Observatoire de Paris, 157 pp., 1996.

Brereton, R. and B. Müller, European stress: contributions from borehole breakouts, Philos. Trans. R. Soc. London, Ser. A, 337, 165-179, 1991.

Campbell, J. and A. Nothnagel, European VLBI for crustal dynamics, $J$. Geodynamics, 30, 321-326, 2000.

Carter, W. E., (ed.), Report of the Surrey Workshop of the IAPSO Tide Gauge Bench Mark Fixing Committee Dec. 1993, NOAA Technical Report, WHOI-89-31, 44 pp., 1994.

Chen, J. L., C. R. Wilson, R. J. Eanes, and R. S. Nerem, Mass variations in the earth system and geocenter motions, in IERS Analysis Campaign to Investigate Motions of the Geocenter, edited by J. Ray, pp. 29-38, IERS Technical Note 25, Observatoire de Paris, 1999.

Davis, J. L., J. X. Mitrovica, H.-G. Scherneck, and H. Han, Investigations of Fennoscandian glacial isostatic adjustment using modern sea level records, J. Geophys. Res., 104, 2733-2747, 1999.

DeMets, C., R. G. Gordon, D. F. Argus, and S. Stein, Effect of recent revisions to the geomagnetic reversal timescale on estimates of current plate motions, Geophys. Res. Lett., 21, 2191-2194, 1994. 
Dong, D., J. O. Dickey, Y. Chao, and M. K. Cheng, Geocenter variations caused by mass redistribution of surface geophysical processes, in IERS Analysis Campaign to Investigate Motions of the Geocenter, edited by J. Ray, pp. 47-55, IERS Technical Note 25, Observatoire de Paris, 1999.

Douglas, B. C., Global sea level rise, J. Geophys. Res., 96, 6981-6992, 1991.

Douglas, B. C., Global sea level acceleration, J. Geophys. Res., 97, 12,69912,706, 1992.

Ekman, M., The world's longest continued series of sea level observations, Pure Appl. Geophys., 127, 73-77, 1988.

Ekman, M., A consistent map of the postglacial uplift of Fennoscandia, Terra Nova, 8, 158-165, 1996.

Gregersen, S., Crustal stress regime in Fennoscandia from focal mechanisms, J. Geophys. Res., 97, 11,821-11,827, 1992.

Grünthal, G. and the GSHAP Region 3 Working Group, Seismic Hazard Assessment for Central, North and Northwest Europe: GSHAP Region 3, Annali di Geofisica, 42, 999-1011, 1999.

Haas, R., E. Gueguen, H.-G. Scherneck, A. Nothnagel, and J. Campbell, Crustal motion results derived from observations in the European Geodetic VLBI network, Earth Planets Space, 52, 759-764, 2000.

Heflin, M. and M. Watkins, Geocenter estimates from the Global Positioning system, in IERS Analysis Campaign to Investigate Motions of the Geocenter, edited by J. Ray, pp. 55-70, IERS Technical Note 25, Observatoire de Paris, 1999.

James, T. S. and A. Lambert, A comparison of VLBI data with the ICE-3G glacial rebound model, Geophys. Res. Lett., 20, 871-874, 1993.

James, T. S. and W. J. Morgan, Horizontal motions due to post-glacial rebound, Geophys. Res. Lett., 17, 957-960, 1990.

Johansson, J. M., J. L. Davis, H.-G. Scherneck, G. A. Milne, M. Vermeer, J. X. Mitrovica, R. A. Bennett, G. Elgered, P. Elósegui, H. Koivula, M. Poutanen, B. O. Rönnäng, and I. I. Shapiro, Continuous GPS measurements of postglacial adjustment in Fennoscandia, 1. Geodetic Results, $J$. Geophys. Res., 2001 (in press).

Kahle, H.-G., M. Cocard, Y. Peter, A. Geiger, R. Reilinger, S. McClusky, R. King, A. Barka, and G. Veis, The GPS strain rate field in the Aegean Sea and western Anatolia, Geophys. Res. Lett., 26, 2513-2516, 1999.

Kakkuri, J. and R. Chen, On horizontal crustal strain in Finland, Bull. Géodesique, 66, 12-20, 1992.

Kijko, A., E. Skordas, R. Wahlström, and P. Mäntyniemi, Maximum likelihood estimation of seismic hazard for Sweden, Natural Hazards, 7 , 41-57, 1993.

Lambeck, K., C. Smither, and M. Ekman, Tests of glacial rebound models for Fennoscandinavia based on instrumental sea and lake level records, Geophys. J. Int., 135, 375-387, 1998.

Milne, G. A., J. X. Mitrovica, and J. L. Davis, Near-field hydro-isostasy: The implementation of a revised sea-level equation, Geophys. J. Int., 139, 464-482, 1999.

Milne, G. A., J. L. Davis, J. X. Mitrovica, H.-G. Scherneck, J. M. Johansson, and M. Vermeer, Space-based measurements provide insight to the classic problem of Fennoscandian uplift, Science, 291, 2381-2385, 2001.

Mitrovica, J. X. and W. R. Peltier, On post-glacial geoid relaxation over the equatorial oceans, J. Geophys. Res., 96, 20,053-20,071, 1991.

Mitrovica, J. X., J. L. Davis, and I. I. Shapiro, Constraining proposed combinations of ice history and earth rheology using VLBI determined baseline length rates in North America, Geophys. Res. Lett., 20, 2387-2390, 1993.

Mitrovica, J. X., J. L. Davis, and I. I. Shapiro, A spectral formalism for computing three-dimensional deformations due to surface loads, 1 . Theory, J. Geophys. Res., 99, 7075-7101, 1994a.
Mitrovica, J. X., J. L. Davis, and I. I. Shapiro, A spectral formalism for computing three-dimensional deformations due to surface loads, 2. Present-day glacial isostatic adjustment, J. Geophys. Res., 99, 70757101, 1994b.

Muir-Wood, R., The Scandinavian earthquakes of 22 December 1759 and 31 August 1819, Disasters, 12, 223-236, 1988.

Müller, B., M. L. Zoback, K. Fuchs, L. Mastin, S. Gregersen, N. Pavoni, O. Stephansson, and C. Ljunggren, Regional Patterns of tectonic stress in Europe, J. Geophys. Res., 97, 11,783-11,803, 1992.

Pan, M. and L. E. Sjöberg, Estimating present-day postglacial rebound and horizontal movements in Fennoscandia by repeated GPS campaigns in 1993 and 1997, Geophys. Res. Lett., 26, 771-774, 1999.

Pan, M., L. E. Sjöberg, C. J. Talbot, and E. Asenjo, GPS measurements of crustal deformation in Skåne, Sweden, between 1989 and 1996, GFF, 121, 67-72, 1999.

Scherneck, H.-G., J. M. Johansson, J. X. Mitrovica, and J. L. Davis, The BIFROST project: GPS Determined 3-D displacement rates in Fennoscandia from 800 days of continuous observations in the SWEPOS network, Tectonophys., 294, 305-322, 1998.

Scherneck, H.-G., G. A. Milne, J. M. Johansson, J. L. Davis, J. X. Mitrovica, and M. Vermeer, BIFROST project: 3-D crustal motions inferred from 1600 days of continuous GPS observations provide new constraints on Fennoscandian Rebound, EOS, Trans. $A G U, 80$ suppl., F274, 1999.

Skordas, E. and O. Kulhánek, Spatial and temporal variations of Fennoscandian seismicity, Geophys. J. Int., 111, 577-588, 1992.

Slunga, R. S., The Baltic Shield earthquakes, Tectonophys., 189, 323-331, 1991.

Steinberger, B. M., H. Schmeling, and G. Marquart, Large-scale lithospheric stress field induced by global mantle circulation, Earth Planet. Sci. Lett., 186, 75-91, 2001.

Talbot, C. J. and R. Slunga, Patterns of active shear in Fennoscandia, in Earthquakes at North-Atlantic Passive Margins: Neotectonics and Postglacial Rebound, edited by S. Gregersen and P. W. Basham, pp. 441-466, Kluwer, Dordrecht, 1989.

Tushingham, A. M. and W. R. Peltier, ICE-3G: A new global model of late pleistocene deglaciation based upon geophysical predictions of postglacial relative sea level change, J. Geophys. Res., 96, 4497-4523, 1991.

Wdowinski, S., Y. Bock, J. Zhang, P. Fang, and J. Genrich, Southern California permanent geodetic array: Spatial filtering of daily positions for estimating coseismic and postseismic displacements induced by the 1992 Landers earthquake, J. Geophys. Res., 102, 18,057-18,070, 1997.

Webb, F. H. and J. F. Zumberge, An introduction to GIPSY/OASIS-II precision software for the analysis of data from the Global Positioning System, JPL Publ. No. D-11088, Jet Propulsion Laboratory, Pasadena, Cal., 1993.

Wessel, P. and W. H. F. Smith, New version of the Generic Mapping Tools released, EOS Trans. $A G U, \mathbf{7 6}, 329,1995$.

Wieczerkowski, K., J. X. Mitrovica, and D. Wolf, A revised relaxation time spectrum for Fennoscandia, Geophys. J. Int., 139, 68-86, 1999.

Zhang, J., Y. Bock, H. Johnson, P. Fang, S. Williams, J. Genrich, S. Wdowinski, and J. Behr, Southern California permanent GPS geodetic array: error analysis of daily position estimates and site velocities, $J$. Geophys. Res., 102, 18,035-18,055, 1997.

H.-G. Scherneck (e-mail: hgs@oso.chalmers.se), J. M. Johansson, M. Vermeer (e-mail: mv@fgi.fi), J. L. Davis (e-mail: jdavis@cfa.harvard.edu), G. A. Milne (e-mail: g.a.milne@durham.ac.uk), and J. X. Mitrovica (email: jxm@physics.utoronto.ca) 